\title{
The use of percentile-percentile plots to compare differences in seasonal dynamics, illustrated by the case of ground beetles (Coleoptera, Carabidae) reacting to urbanisation
}

\author{
G. L. Lövei1 ${ }^{1,5}$, Z. Elek ${ }^{2,5}$, A. Howe ${ }^{3}$ and M. Engaard ${ }^{4}$ \\ ${ }_{1}^{1}$ Department of Agroecology, Aarhus University, Flakkebjerg Research Centre, DK-4200 Slagelse, Denmark. \\ Corresponding author.Tel.: +45-87158224, e-mail: gabor.lovei@agro.au.dk \\ ${ }_{2}^{2}$ MTA-ELTE-MTM Ecology Research Group, Biological Institute, Eötvös Loránd University, Pázmány Péter sétány 1C, \\ H-1117 Budapest, Hungary \\ ${ }^{3}$ Department of Geosciences and Natural Resource Management, University of Copenhagen, 1958 Frederiksberg C, \\ Denmark \\ 4909 Duke Street Alexandria 22314 Virginia, USA \\ ${ }_{5}^{5}$ These authors equally contributed to the paper.
}

Keywords: Carabids, Globenet, Graphical description, Rural-urban gradient, Seasonality.

\begin{abstract}
We suggest the use of a graphical method, involving a standardisation of the seasonal activity curves and their subsequent comparison by a percentile-percentile graph as an easy way to compare seasonal activities in arthropods. To test the suitability of the suggested method, the seasonal dynamics of three common carabid beetles, Pterostichus melanarius, Nebria brevicollis and Carabus nemoralis were compared in three habitats (rural forest, suburban and urban forest fragments) along an urbanisation gradient near Sorø, Denmark, in 2004 and 2005. Activity in urban habitats often started earlier, possibly caused by the warmer microclimate in the city centre. The comparative graphs indicated the unsuitability of the suburban habitat for N. brevicollis, and the differential suitability as overwintering habitat of the three urbanisation stages for $C$. nemoralis. The method seems suitable to analyse differences in seasonal activity while being more sensitive than traditional seasonal-activity graphs.
\end{abstract}

\section{Introduction}

Ground beetles are good ecological indicators because they are sufficiently varied both taxonomically and ecologically, abundant in many habitats and sensitive to many kinds of disturbance (Lövei and Sunderland 1996). Carabids can react to environmental changes at different organisational levels. Within-individual level reactions include changes in enzyme activities or gene frequency; individual-level changes include behavioural changes and changes in seasonal phenology. At the population level, population parameters, such as mortality rates or habitat preference could change; at assemblage level, changes in assemblage composition (Magura et al. 2010), or size distribution (Magura et al. 2006) can occur. These levels have their own time scale, and lower level reactions are typically faster than higher level ones. Most of the papers dealing with carabids and bioindication concentrate on higher level responses (review in Rainio and Niemelä 2003, Koivula 2011). However, features linked to behaviour may be more sensitive and more immediate than life history parameters that are dependent on development duration and population life span, and typically require a longer time to manifest themselves.

One rapidly changing parameter reflecting behavioural change in response to environmental conditions (i.e., prey availability, habitat quality, disturbance regimes, etc.) is sea- sonal activity. Environmental changes could trigger a delay in the start of activity, or change the timing of activity peaks. Such reactions are faster than those in population parameters, and can thus signal environmental change earlier than population- or community-level parameters, provided reliable indicators of such reactions are available.

Data analysts (e.g., Cleveland 1993) emphasise the suitability of graphical data exploration methods in analysing scientific data. Such methods are simple, very useful to generate hypotheses for further analysis, yet are often neglected. A simple graphical technique to visualise the comparison of activity curves is the percentile-percentile plot (p-p plot) of Wilk and Gnanadeshikan (1968). Apparently, this method has not been used in entomology or ecology (literature search on Web of Science in November 2017, found no relevant articles). The method relies on the ability of the eye to detect and easily interpret even small deviations from the perfect diagonal line. We use this technique to examine our material collected in the urbanisation research project, Danglobe (Elek and Lövei 2005).

One of the most prominent and widespread recent environmental change can be linked to urbanisation. During advancing urbanisation, ground beetle assemblages undergo a substantial rearrangement indicating a general decrease in habitat quality. However, species reactions are different: certain forest specialist species become rare or disappear, while 
other species only appear at the most urbanised habitats (Magura et al. 2010). By the evaluation criteria so far applied in published Globenet studies (species presence, total activity density over the season), generalist or ubiquitous species did not show significant trends in response to increasing disturbance as a result of urbanisation.

During the analysis of our results of the Danglobe Project (Elek and Lövei 2007), we formulated a "differential activity hypothesis", which suggests that the activity profiles of individual species reflect habitat quality. In an unfavourable habitat, we expect that the beetles have high activity in the early part of the season, because their fat reserves are depleted and their survival will depend on finding food immediately after emergence from hibernation. Most generalist predators that emerge from winter inactivity find themselves in this situation (Bilde et al. 2000). After an initial burst of activity, they are forced to emigrate from such an unfavourable habitat due to lack of food. Beetles in less favourable habitats can also show late bursts of activity density, when individuals developed in other, more favourable habitats may "spill over" into habitats with less favourable conditions (Rand et al. 2006). If only yearly totals are considered (as is the case for most published studies in the Globenet Projects, e.g., Niemelä et al. 2002, Magura et al. 2004), these aspects remain hidden. The differential activity hypothesis compares individual species, and can be applied to common species that occur in the habitats to be compared.

The aim of this paper is to demonstrate the usefulness of the "p-p plot" technique in the comparative analysis of ground beetle activity. We use the technique to test the abovedescribed "differential activity hypothesis" at different urbanisation stages in Sorø, Denmark. We also compared the p-p plot and the traditional seasonal-activity plots to demonstrate the use of this new graphical tool.

\section{Material and methods}

We collected our material within the framework of the Globenet Project, which aims to assess the influence of urbanisation on biodiversity (Niemelä et al. 2000). This project applies the rural-urban gradient approach (Pickett et al. 2001) using a common methodology (pitfall trapping) and evaluates the responses of a common invertebrate taxon (ground beetles, Carabidae) to urbanisation. In the Globenet project, three kinds of forested habitats (rural forest, suburban forested area and remnants of the original forest as patches in urban parks) are compared, which represent different degrees of urbanisation, and an increasing level of anthropogenic disturbance. The study area was in and around the town of Sorø, $80 \mathrm{~km}$ west of Copenhagen, on the island of Zealand, Denmark (Elek and Lövei 2005). Three urbanisation stages were selected according to the requirements of the Globenet protocol (Niemelä et al. 2000): all were part of the once-continuous beech forest surrounding Sorø, but today they are fragmented to different degrees.

The rural area was in an extensive, lightly thinned nearcontinuous forested area, ca. $3 \mathrm{~km}$ west from the town centre, bordered - on one side - by Lake Sorø and the outskirts of the town. The suburban area was northeast of the town centre. On one side, it was bordered by an old cemetery and a weekend garden allotment zone. An old ditch, a dirt road and a wet forest area under intensive forestry management was on the other side. This area started ca. $1 \mathrm{~km}$ from the edge of the Sorø Akademi Park. The built-up area and covered road surface amounted to approximately $20 \%$; the un-
Figure 1. An example of the comparative activity plots of three hypothetical pairs of datasets. The one with empty circles indicates two activity curves that are not different from each other. The curve with full circles indicates a relationship where activity at Site 2 is consistently earlier than at Site 1, and the curve with triangles indicates that activity at Site 1 is earlier than at Site 2.

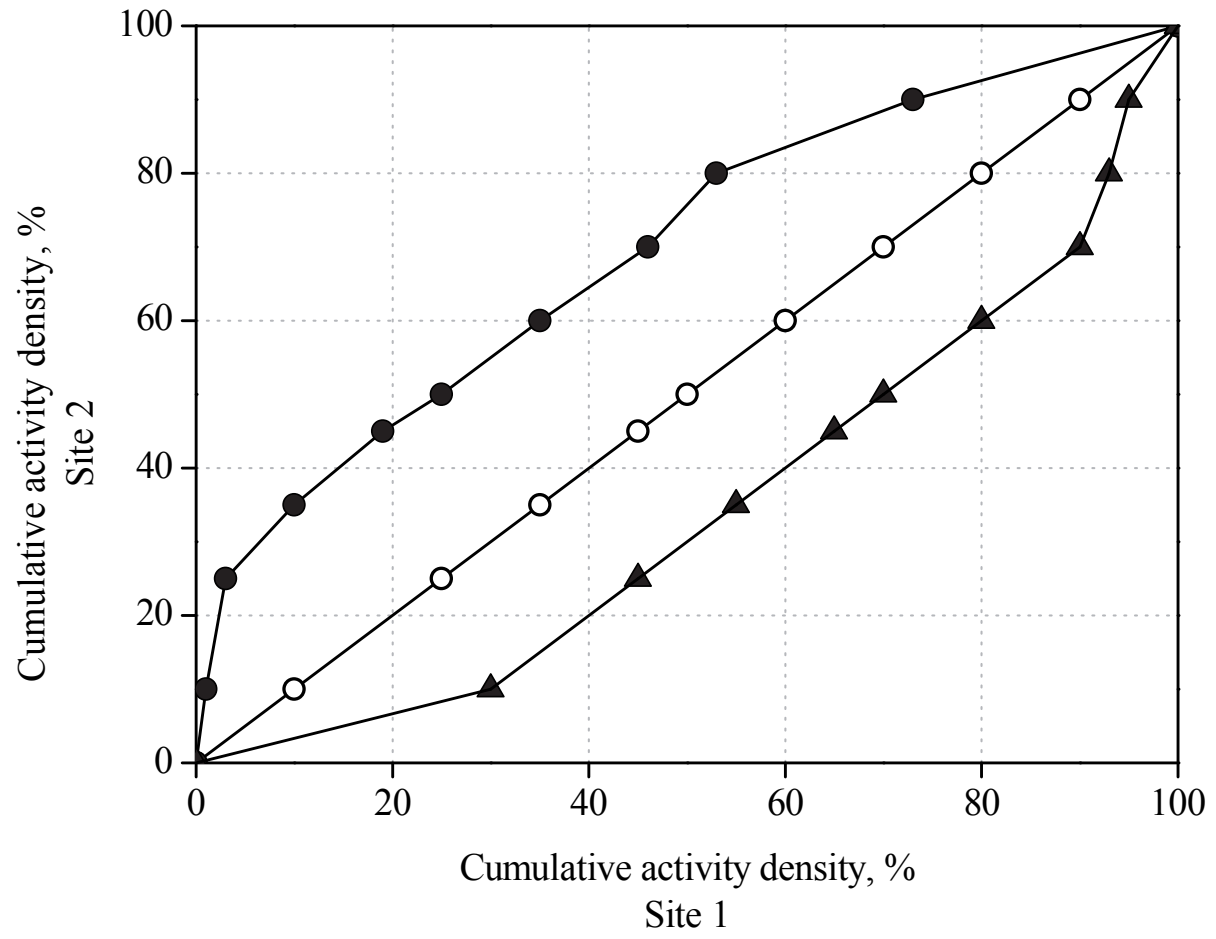


derstory indicated nitrogen-rich soil (plenty of nettle, Urtica dioica). The urban area was composed of forest patches in the park complex of the Sorø Akademi. The park is "softly" managed: there are only gravel but no asphalt-covered paths, and the mown grass, leaf litter and cut branches are returned to the understory of the forested patches. The built-up area was about $40 \%$. The park is isolated: on one side, there is the Sorø Lake, on the other, the city centre.

Following the Globenet protocol (Niemelä et al. 2000), individual traps were placed at least $10 \mathrm{~m}$ apart at each site; five traps formed a group, separated by at least $20 \mathrm{~m}$ from the next group; two such groups (10 traps) formed a site. Four sites, at least $300 \mathrm{~m}$ from each other, were selected within each sampling area. This arrangement contained 120 traps along the rural-urban gradient ( 3 areas $\times 4$ sites $\times 10$ traps).

Traps were checked fortnightly between the end of April to mid-October, 2004, giving a trapping effort of 2640 trapweeks (120 traps $\times 22$ weeks). In 2005, trapping was conducted every second fortnight, with a total sampling effort of 1440 trap-weeks (120 traps $\times 12$ weeks; Sapia et al. 2006). For identification, keys by Lindroth $(1985,1986)$ and Hůrka (1996) were used. The total material collected was 10314 individuals of 43 species in 2004, and 4961 individuals of 38 species in 2005 (Elek et al. 2017).

\section{Comparing seasonal activity among different urbanisation stages}

Seasonal activity among the different urbanisation stages was compared using the "percentile-percentile (p-p) plot" (Wilk and Gnanadeshikan 1968, Cleveland 1993). When constructing a p-p plot, the following steps are taken:

1. Prepare quantile plots (Fazekas et al. 1997) or tables of the two capture series to be compared.

2. Plot the two cumulative capture series against each other. Be aware that the points have to represent the cumulative captures at the same time in the two data series. Occasional interpolation of one data point is allowed. Let us assume that the first data point along the $\mathrm{x}$ axis is $20 \%$. To find the corresponding data point in series 2 , first find the date belonging to the point on the graph of series 1 (constructed as indicated under point 1), then look up the value on that same date on series 2. Do this for all points along the seasonal graph. If the two datasets have the same seasonal distribution, the points will fall on the diagonal line (Fig. 1). Deviations from this reference line indicates differences in seasonal activity (depicted, for demonstration only, by two other lines in Fig. 1).

While the two data series do not have to be collected during precisely the same period, the time axis over which the seasonal graph is compared should be identical. In such cases, the start of the graph should be the date of the series with the earlier start, and the end should be that of the latter one. All comparisons should use identical time axes. To help interpretation, dates can be indicated as labels along the diagonal axis (see Figs 2-3 and Fig. S1 in Supplementary Material).

We suggest that these plots are called "comparative activity plots". In order to illustrate their use, we compared the seasonal
Table 1. Activity density (no. of individuals/trap $\times$ week) of $P$. melanarius, $C$. nemoralis and $N$. brevicollis in forests or forest fragments, and their total numbers captured along an urbanisation gradient in Sorø, Denmark, 2004-2005.

\begin{tabular}{lccc}
\hline \multicolumn{1}{c}{ Year, habitat } & \multicolumn{3}{c}{ Species } \\
\hline & $\begin{array}{l}\text { Pterostichus } \\
\text { melanarius }\end{array}$ & $\begin{array}{l}\text { Carabus } \\
\text { nemoralis }\end{array}$ & $\begin{array}{l}\text { Nebria } \\
\text { brevicollis }\end{array}$ \\
\hline 2004 & & & \\
$\quad$ Rural forest & 629 & 148 & 173 \\
$\quad$ Suburban & 98 & 271 & 115 \\
Urban & 1780 & 309 & 846 \\
2005 & & & \\
$\quad$ Rural forest & 275 & 46 & 259 \\
$\quad$ Suburban & 53 & 170 & 302 \\
$\quad$ Urban & 471 & 85 & 891 \\
Total & 3306 & 1029 & 2586 \\
\hline
\end{tabular}

activity of some common ground beetle species collected in the Danglobe Project (Elek and Lövei 2007). We considered species from which $\geq 10$ individuals/year were collected at each of the three studied habitats (rural forest, suburban and urban) in both years. Three species fulfilled these conditions: Pterostichus melanarius Illiger 1798, Nebria brevicollis F. 1792 and Carabus nemoralis Müller 1764.

\section{Results}

\section{Seasonal activity comparisons, Pterostichus melanarius}

The activity density of this species was the highest in the urban habitat in both years (Table 1). The comparative graphs (Fig. 2) indicate that the seasonal activity was largely similar in the three habitats in 2004 (except an early activity burst in the suburban habitat). In 2005, beetles in the rural forest were active earlier than in the suburban or, to a lesser degree, in the urban habitat (Fig. 2). In the suburban-urban comparison, activity was similar in the early part of the season but ended earlier in the urban habitat than the suburban one (Fig. 2). The comparison of these graphs with the traditional seasonalactivity ones (Fig. S1) showed that the activity comparison plots (i.e. p-p lots) were more suitable to interpret the complex spatio-temporal patterns in activity density. For P. melanarius, it was difficult to perceive that their activity-density was higher in the urban habitats when we used the traditional seasonal activity graphs (Fig. S1).

\section{Seasonal activity comparisons, Nebria brevicollis}

The activity density of this species was highest in the urban habitat in both years (Table 1), but the species displayed large differences in seasonal activity among the different habitats (Fig. 3). Adults were active earlier in the rural forest and urban habitats than in the suburban one in 2004 (Fig. 3). This difference was especially large between the urban and suburban habitats (Fig. 3). In late summer, there was a rapid increase of activity in the suburban habitat - this happened later than in the other two urbanisation stages. In 2005, the 
activity density of $N$. brevicollis was higher than in 2004, especially in the latter half of the season. However, similar between-habitat trends were found (Fig. 3). These trends were not evident on the traditional graphs (Fig. S2)
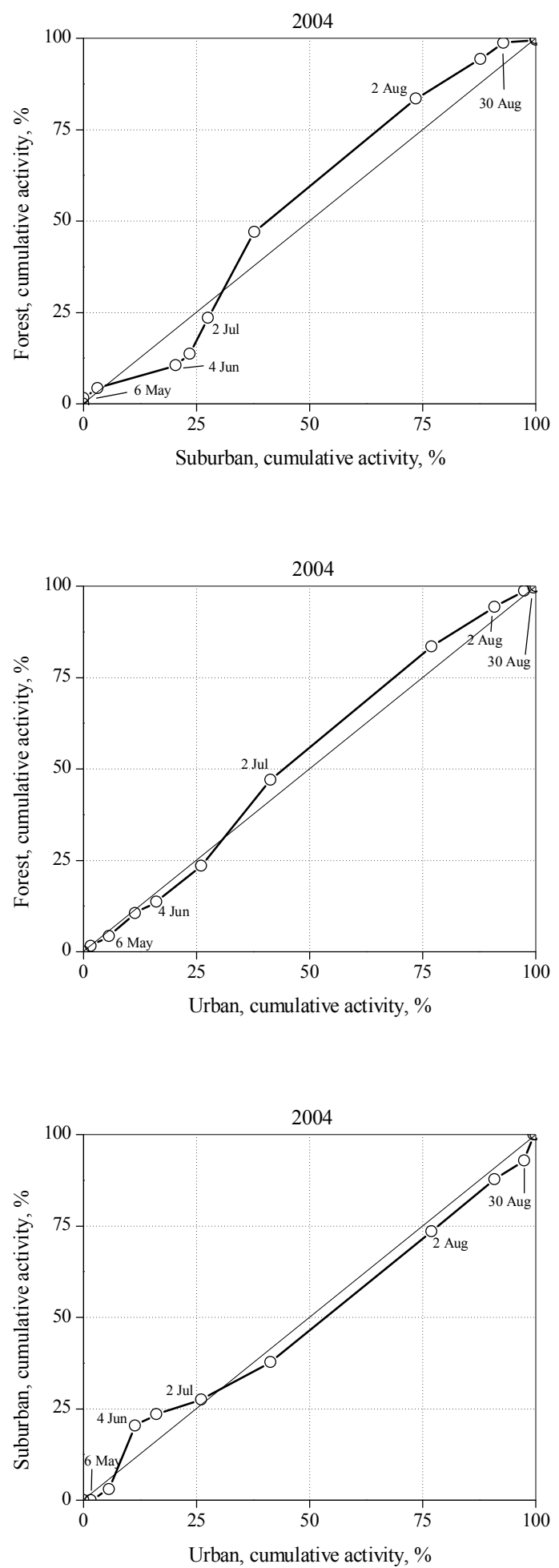

Seasonal activity comparisons, Carabus nemoralis

The activity density of this species was the highest in the urban habitat in 2004, while in the suburban one in 2005
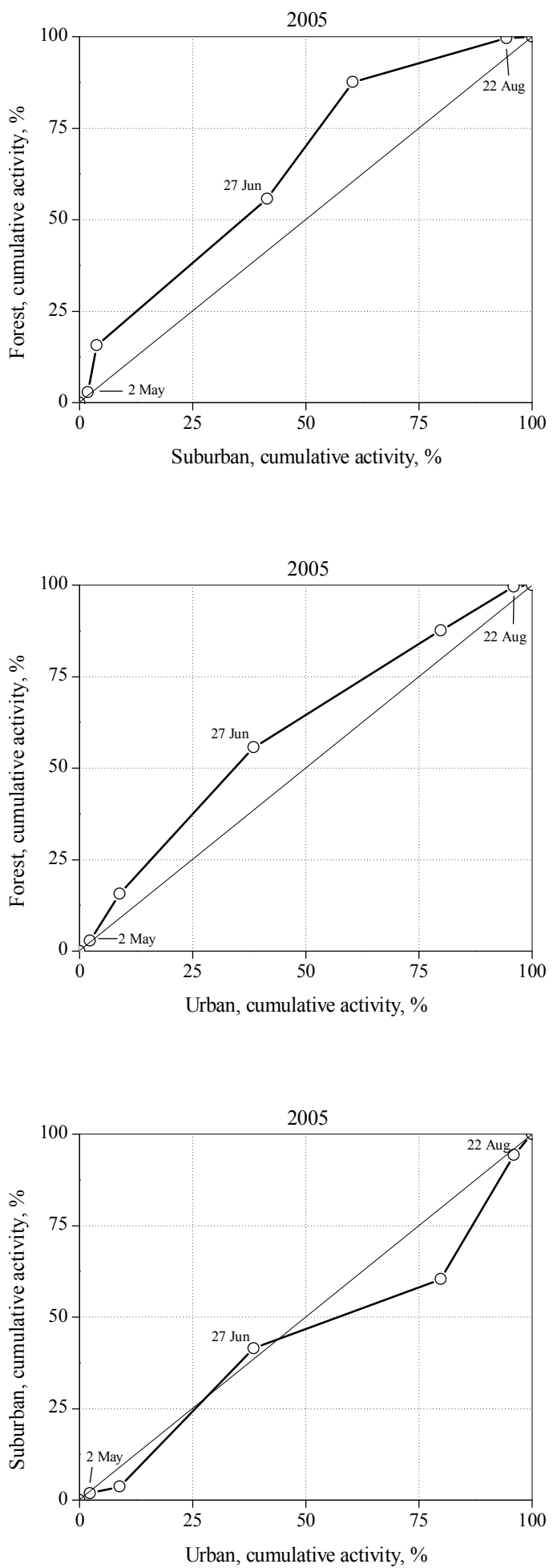

Figure 2. Comparative activity plots for Pterostichus melanarius in rural, suburban and urban habitats at Sorø, Denmark, during the sampling periods in 2004 and 2005. 
(Table 1). In 2004, the activity in the rural forest and suburban habitats was similar, apart from a late summer burst of adult activity in the forest (Fig. 4). This trend was much more pronounced in 2005 (Fig. 4). The rural forest-urban forest patch comparison indicated that adults were active earlier in the urban than the rural habitat, and showed a steep autumn activity increase in the latter, especially in 2005 (Fig. 4). Comparing the suburban and urban habitats, both the spring and autumn
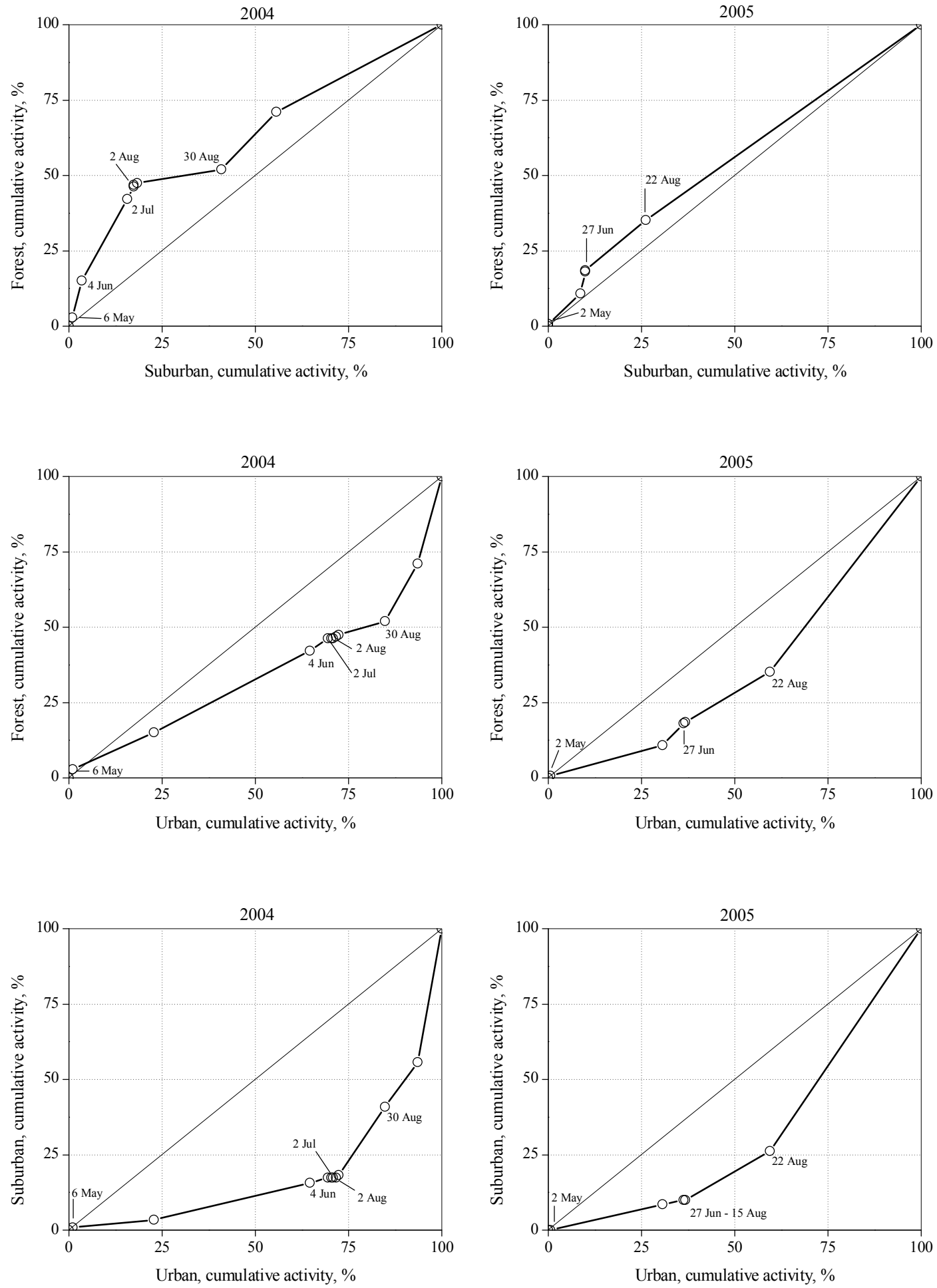

Figure 3. Comparative activity plots for Nebria brevicollis in rural, suburban and urban habitats at Sorø, Denmark, during the sampling periods in 2004 and 2005 
activities started earlier in the urban than the suburban habitats in both years (Fig. 4). The activity comparison plots (Fig. S3) identified the differences in activity density in the suburban vs. urban habitats in 2004 and between the rural and the urban ones in 2005.
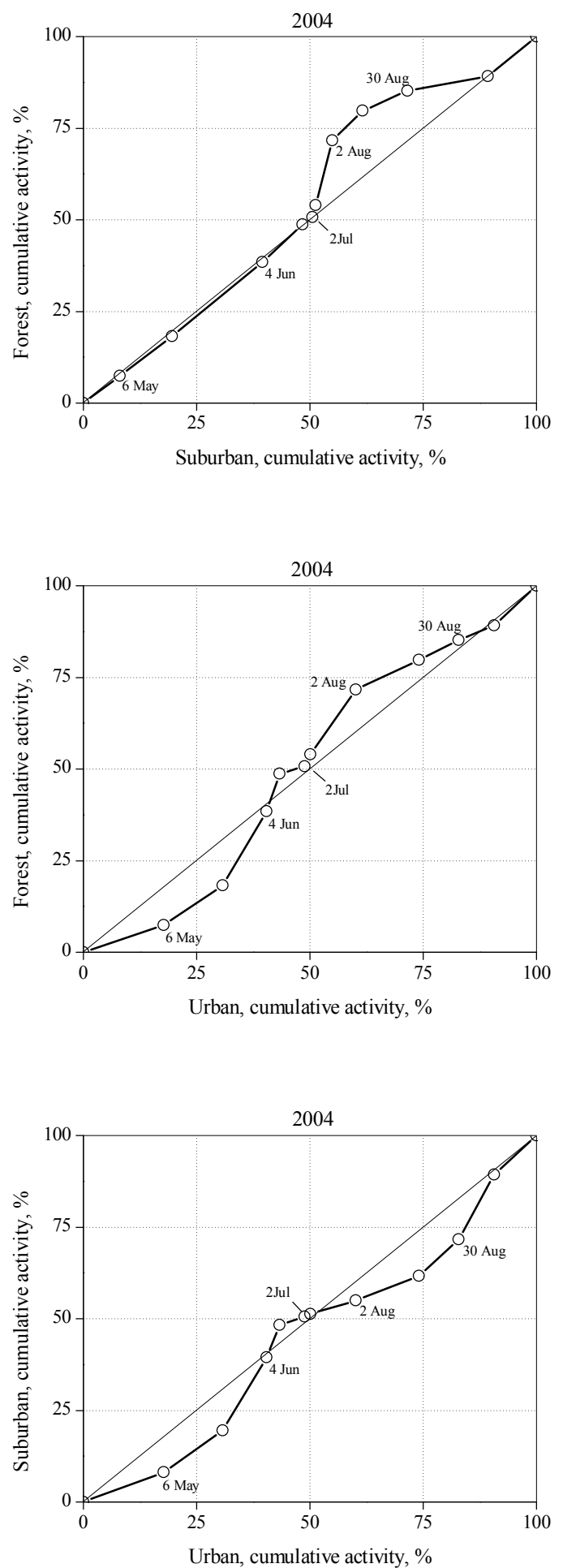

\section{Discussion}

Carabids in the temperate region are generally most active during spring and summer and show clear seasonality (Thiele, 1977). This was also the case in Sorø, but we found a remarkable difference in the activity pattern of the common
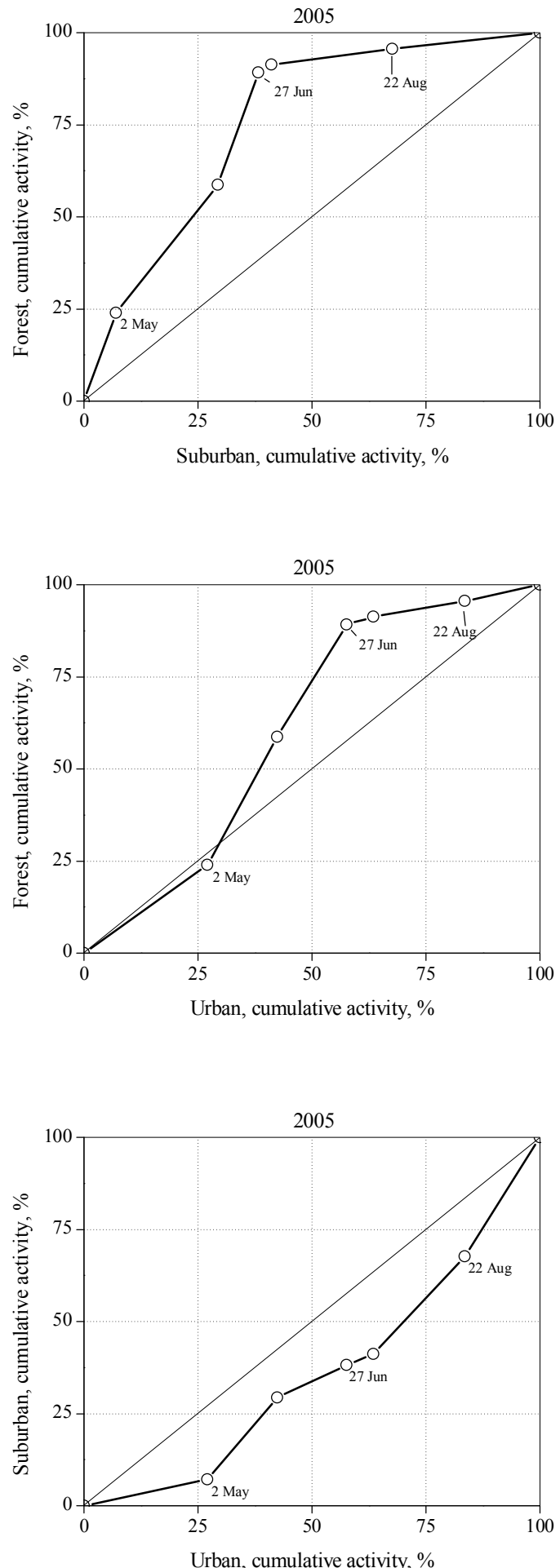

Figure 4. Comparative activity plots for Carabus nemoralis in rural, suburban and urban habitats at Sorø, Denmark, during the sampling periods in 2004 and 2005. 
ground beetles species in the habitats that belong to different urbanisation stages.

P. melanarius, a habitat generalist (Thiele 1977, Desender et al. 2008) was less affected by urbanisation, showing no major differences in seasonal activity among the habitats and years. This species hibernates as an adult, and this can enable it to survive (and reproduce) in suboptimal habitats.

$N$. brevicollis is a more strictly carnivorous species, and its activity pattern showed noticeable differences among the habitats and dates. This species was more active in the urban habitat than elsewhere, mainly in the early summer period. During this time the changes in the abundance occurred rapidly, because of the emergence of teneral adults which leads to an explosion in the number of individuals (Penney 1969). The comparison also revealed that the suburban habitat was not optimal for this species: large numbers only occurred here after the appearance of the new generation, manifested in an activity burst in the urban habitat. The beetles captured later in the suburban habitats could be immigrants from the urban one. In the rural forest, the delayed activity peak could indicate a slower development of larvae, which could reflect the lower temperatures occurring in such habitats (Magura et al. 2008).

C. nemoralis is a habitat generalist (Thiele 1977, Desender et al. 2008). Differences between years, more in numbers than in the shape of the comparative curves, could be influenced by the overwintering success of the adults, indicating the suitability of their overwintering habitats. In this respect, the value of suburban and urban habitats was similar, while the rural forest seemed to be better.

In several cases, we found an earlier onset or higher level of activity in the urbanised area than in the other habitats. As forest fragments were smaller in the urbanised habitats than the two other urbanisation stages, the "heat island" effect of urban areas (McKinney 2006), can make the temperature in these fragments higher, extending the activity period of adults and allowing a faster development of larvae.

The study of seasonal dynamics of invertebrates is important, because it can help to clarify the ecological pattern against a background of confounding factors (Ewers and Didham 2006). Differential changes in the activity curve hinted at differences in habitat suitability for larval development (in $N$. brevicollis) or overwintering (in C. nemoralis), generating hypotheses about the causes of these differences that can be tested in experiments. Other factors, such as the density, kind and activity of natural enemies (Lövei and Sunderland 1996), prey availability, and habitat structure (Thiele 1977) could also influence activity, directly or indirectly.

We suggest that the proposed graphical method is an easy and intuitive way of comparing seasonal dynamics. Using comparative activity ( $p-p)$ plots revealed patterns not evident when comparing sites with traditional seasonal-activity curves. Comparative p-p plots can be useful for a more sophisticated analysis of invertebrate reactions to changes in habitat conditions. Quantification of differences for comparisons would be possible by quantifying the area of deviation from the diagonal line, similar to the suggestions to evaluate differences in size distribution by Magura et al. (2006). As many graphical methods, comparative p-p plots can be a very useful tool to conceptualise complicated phenomena, to generate hypotheses, and to direct further analyses (Cleveland 1993).

Acknowledgements: We thank the Sorø Akademi Stilftelse for permission to work on their land, Director Mr. J. Thomsen and Mr. A. Grube for their kind assistance, Dr. J. Jakobsen for support, Mrs. H-B. Christiensen for technical assistance, Dr. H-P. Ravn and Dr. M. Pedersen for comments. This study was partially funded by the Danish International School for Biodiversity Studies (ISOBIS) (ZE), the Hungarian Scholarship Board (ZE), Aarhus University, Flakkebjerg Research Centre, the Department of Life Sciences and Chemistry, University of Roskilde (AH, ME) and the Domus Hungarica Foundation, Budapest, Hungary (GLL). This is publication no. 10 of the Danglobe Project. Author contributions: GL originally formulated the idea, developed methodology, fieldwork was done by ZE, AH and ME, with assistance from GL, ZE and GL collaborated in the statistical analysis of data, GL and ZE wrote the manuscript. Authorship follows the "sequence by merit" principle.

\section{References}

Bilde, T., J.A. Axelsen and S. Toft. 2000. The value of Collembola from agricultural soils as food for a generalist predator. J. Appl. Ecol. 37:672-683.

Cleveland, W.S. 1993. Visualizing Data. AT\&T Bell Laboratories, Murray Hill, New Jersey, USA.

Desender, K., W. Dekoninck, D. Maes, L. Crevecoeur, M. Dufrêne, M. Jacobs, J. Lambrechts, M. Pollet, E. Stassen and N. Thys. 2008. Een nieuwe verspreidingsatlas van de loopkevers en zandloopkevers (Carabidae) in België.[INBO.R.2008.13]. Rapporten van het Instituut voor Natuur- en Bosonderzoek, 2008(13). Instituut voor Natuur- en Bosonderzoek, Brussel, Belgium.

Elek, Z. and G.L. Lövei. 2005. Ground beetle (Coleoptera, Carabidae) assemblages along an urbanisation gradient near Sorø, Zealand, Denmark. Entomol. Medd. 73:115-121.

Elek, Z. and G.L. Lövei. 2007. Patterns in ground beetle (Coleoptera: Carabidae) assemblages along an urbanisation gradient in Denmark. Acta Oecol. 32:104-111.

Elek, Z., A. Howe, M. Engaard and G.L. Lövei. 2017. Seasonal dynamics of common ground beetles (Coleoptera, Carabidae) along an urbanisation gradient near Sorø, Zealand, Denmark. Entomol. Fenn. 28:27-40.

Ewers, R.M. and R.K. Didham. 2006. Confounding factors in the detection of species responses to habitat fragmentation. Biol. Rev. 81:117-142.

Fazekas, J., F. Kádár, M. Sárospataki and G.L. Lövei. 1997. Seasonal activity, age structure and egg production of the ground beetle Anisodactylus signatus (Coleoptera: Carabidae) in Hungary. Eur. J. Entomol. 94:473-484.

Hůrka, K. 1996. Carabidae of the Czech and Slovak Republics. Kabourek, Zlin, Czech Republic.

Lindroth, C.H. 1985. The Carabidae (Coleoptera) of Fennoscandia and Denmark. Fauna Entomologica Scandinavica, Vol. 15, part 1. E.J. Brill, Leiden, The Netherlands. 
Lindroth, C.H. 1986. The Carabidae (Coleoptera) of Fennoscandia and Denmark. Fauna Entomologica Scandinavica, Vol. 15, part 2. E.J. Brill, Leiden, The Netherlands.

Koivula, M. 2011. Useful model organisms, indicators, or both? Ground beetles (Coleoptera, Carabidae) reflecting environmental conditions. Zookeys 100:287-317.

Lövei, G.L. and K.D. Sunderland. 1996. Ecology and behavior of ground beetles (Coleoptera: Carabidae). Ann. Rev. Entomol. 41: 231-256.

McKinney, M.I. 2006. Urbanisation as a major cause of biotic homogenization. Biol. Cons. 127:247-260.

Magura, T., B. Tóthmérész and G.L. Lövei. 2006. Body size inequality of carabids along an urbanisation gradient. Basic Appl. Ecol. $7: 472-482$

Magura, T., G.L. Lövei and B. Tóthmérész. 2010. Does urbanisation decrease diversity in ground beetle (Carabidae) assemblages? Global Ecol. Biogeogr. 19:16-26.

Magura, T., B. Tóthmérész and T. Molnár. 2004. Changes in carabid beetle assemblages along an urbanisation gradient in the city of Debrecen, Hungary. Landscape Ecol. 19:747-759.

Magura, T., B. Tóthmérész and T. Molnár. 2008. A species-level comparison of occurrence patterns in carabids along an urbanisation gradient. Landscape Urban Plan. 86:134-140.

Niemelä, J., D.J. Kotze, A. Ashworth, P. Brandmayr, K. Desender, T. New, L. Penev, M. Samways and J. Spence. 2000. The search for common anthropogenic impacts on biodiversity: a global network. J. Ins. Conserv. 4:3-9.

Niemelä, J., D.J. Kotze, S. Venn, L. Penev, I. Stoyanov, J. Spence, D. Hartley and E.M. de Oca. 2002. Carabid beetle assemblages (Coleoptera, Carabidae) across urban-rural gradients: an international comparison. Landscape Ecol. 17:387-401.

Penney, M.M. 1969. Diapause and reproduction in Nebria brevicollis (F.) (Coleoptera: Carabidae). J. Anim. Ecol. 38:219-233.

Pickett, S.T.A., M.L. Cadenasso, J.M. Grove, C.H. Nilon, R.V. Pouyat, W.C. Zipperer and R. Costanza. 2001. Urban ecological systems: linking terrestrial ecological, physical, and socioeconomic components of metropolitan areas. Annu. Rev. Ecol. Evol. Syst. 32:127-157.

Rainio, J., and J. Niemelä. 2003. Ground beetles (Coleoptera: Carabidae) as bioindicators. Biodiv. Conserv. 12:487-506.

Rand T. A., J.M. Tylianakis and T. Tscharntke. 2006. Spillover edge effects: the dispersal of agriculturally subsidized insect natural enemies into adjacent natural habitats. Ecol. Lett. 9:603-614.

Sapia, M., G.L. Lövei and Z. Elek. 2006. Effects of varying sampling effort on the observed diversity of carabids (Coleoptera: Carabidae). Entomol. Fenn. 17:345-350.

Thiele, H.U. 1977. Carabid Beetles in their Environments. Springer, Berlin, Germany.

Wilk, M.B. and R. Gnanadesikan. 1968. Probability plotting methods for the analysis of data. Biometrika 55:1-17.

Received November 19, 2017 Revised December 14, 2017

Accepted January 6, 2018

\section{Supplementary material}

Figure S1. Seasonal dynamics of Pterostichus melanarius at the three urbanisation stages (rural forest, suburban, and urban forest remnants) in Sorø, West Zealand, Denmark.

Figure S2. Seasonal dynamics of Nebria brevicollis at the three urbanisation stages (rural forest, suburban, and urban forest remnants) in Sorø, West Zealand, Denmark.

Figure S3. Seasonal dynamics of Carabus nemoralis at the three urbanisation stages (rural forest, suburban, and urban forest remnants) in Sorø, West Zealand, Denmark.

The file may be downloaded from www.akademiai.com. 